\title{
CFD Simulation of Silica Gel as an Adsorbent on Finned Tube Adsorbent Bed
}

\author{
Andre Kurniawan, Nasruddin*, Asep Rachmat \\ Mechanical Engineering Department, Faculty of Engineering, Universitas Indonesia, Depok 16425, Indonesia
}

\begin{abstract}
The adsorption technology is becoming the more expected solution by today's researchers for fix the energy and environmental issues. The main part of the cooling system adsorption is adsorbent and adsorbate. One of the most widely used adsorbents in research of adsorption technology is silica gel. A new silica gel-water adsorption chiller design was developed that composed of two sorption chambers with compact fin tube heat exchangers as adsorber, condenser, and evaporator. Energy, mass, and momentum conservation equations of the adsorption systems have been used for the CFD two and three dimensional models. The geometry of simulation is simply made within silica gel layer between two fins. The simulation is also implemented using a finite volume method through the CFD software Fluent. User defined functions are given to modify the energy, mass, and momentum conservation equations. The simulation of adsorption process is adjusted at unsteady condition. Adsorption and desorption processes are simulated with room temperature for cooling water inlet at temperature $305.15{ }^{\circ} \mathrm{K}$, hot water inlet at temperature $353.15{ }^{\circ} \mathrm{K}$, mass flow rate cooling water inlet at $0.3 \mathrm{~kg} / \mathrm{s}$ and pressure $32 \mathrm{KPa}$. For the whole adsorbent bed area, the result shows that the highest absolute adsorption rate at the outer surface, while the lowest rate is at the center. After adsorption was finished, the condition is reversed. The highest absolute adsorption rate is achieved at center, while the lowest rate is achieved at the outer surface.
\end{abstract}

\section{Introduction}

Adsorption cooling technology in chillers has become a notable popularity as an alternative to conventional vapour compression chillers. Adsorption coolers have significant advantages today such as suitable for low thermal energy in the form of waste heat or solar energy. As natural coolants such as water, ethanol, methanol, $\mathrm{CO} 2$, ammonia, it has additional advantages that include zero global warming potential (GWP) and ozone depletion (ODP). The maintenance is easy because there is no moving part.

But some constraints such as low coefficient of performance (COP) and specific cooling power (SCP), size of the mass and the volume that is less ergonomic, as well as high initial procurement investment become challenges in implementing this technology on massive scale. Researchers working on this field are also looking for ways to improve the efficiency of their own adsorption cooling technology, such as develop several new refrigerants with high uptake [1-4], attempt variations in the use of adsorbents [5-8], improvise heat transfer coefficients [9-11], attempt variations of cycle time [12-13], and apply the heat recovery and the mass recovery process [14].

Specific topic that requires special attention to the adsorption cooling system is the performance of the adsorbent bed which is one of the most important parts in the chiller. However, research on CFD
(Computational Fluid Dynamics) simulation on adsorbent bed in adsorption cooling system is still very rare. Some researches that are similar to the topic of related discussion have been largely done by experts. Sahoo, et al (2011), has conducted ANG research simulation using COMSOL MULTIPHYSICS 3.5a. software with a symmetric 2D-axis geometry model for the distribution of temperature and pressure at adsorption and for the variation of bed size. Nouh, et al (2010), has conducted a 3D model simulation using Fluent software to find out the adsorption capacity that included $\mathrm{CO}_{2}$ and $\mathrm{CH}_{4}$ gas mixtures with variations of speed and porosity. Xiao, et al (2013), has performed simulation using Fluent software to determine the adsorption capacity and the distribution of pressure and temperature. The study was conducted on hydrogen gas with $2 \mathrm{D}$ symmetric axis model and facilitated by CFDs that help analysing the temperature, pressure, and adsorption during the experiment.

The silica gel-water adsorption cooling system can be driven by low temperature heat source in range from 60 to $95{ }^{\circ} \mathrm{C}$ [15]. So, the simulation will be run at some variation of hot water input temperatures. The silica gelwater adsorption phenomena can be described as contour of the temperature, pressure, and adsorption. It can be described by using the $2 \mathrm{D}$ geometry model or the $3 \mathrm{D}$ geometry model within the porosity model. So the simple 3D model (2D model with thickness) is used to get more detail about the phenomena.

\footnotetext{
* Corresponding author: nasruddin@eng.ui.ac.id
} 


\section{Mathematical model}

\subsection{Adsorption model}

In this work, the adsorption for adsorbent bed model cumulate models for the adsorption isosteric heat and the adsorption isotherms. An adsorption isotherms model in adsorbent can be performed by the modified DubininAstakhov (D-A) model. The absolute adsorption isotherm for the system is defined as [16]:

$$
\left.n_{\alpha}=n_{0} \exp \left[-\left(\frac{R T}{\alpha+\beta T}\right)^{m} \ln \frac{p^{m}}{p}\right)\right]
$$

where the $n_{0}$ value is $71.6 \mathrm{~mol} / \mathrm{kg}$ which is the maximum adsorption value. The $m$ value is 2 . The $R$ value is $8.314 \mathrm{~J} / \mathrm{mol}$ which is the universal gas constant. The $p$ is the equilibrium pressure. The $p_{0}$ value is $1.47 \mathrm{e} 9$ $\mathrm{Pa}$ which is the saturation pressure. The parameters $\alpha$ is the enthalpic factor which is equal to $3080 \mathrm{~J} / \mathrm{mol}$ and parameter $\beta$ is the entropic factors which is equal to 18.9 $\mathrm{J} /(\mathrm{mol} \mathrm{K})$.

The adsorption isosteric heat decreasing during adsorption and increasing during desorption. The adsorption heat can be specified as [17]:

$$
\Delta H=\alpha \sqrt{\ln \left(n_{0} / n_{⿷}\right)}
$$

\subsection{Conservation of mass}

The mass conservation equation in porous media is defined as [19]:

$$
\frac{\partial\left[s_{\mathrm{h}} \rho_{g}\right]}{\partial t}+\nabla \cdot\left(\rho_{g} \vec{v}\right)=S_{m}
$$

where $S_{m}\left(\mathrm{~kg} / \mathrm{m}^{3} \mathrm{~s}\right)$ is the mass source term. The mass source term models the mass added from the gas phase to the absorbed phase in unit volume per second. It can be expressed as:

$$
S_{m}=-\frac{\partial}{\partial t}\left(p_{b} q_{a}\right)
$$

The bed density, $\rho_{b}\left(\mathrm{~kg} / \mathrm{m}^{3}\right)$, and mass ratio of adsorbate to adsorbent, $q_{a}$, are defined as:

$$
\begin{gathered}
\rho_{b}=\left(1-\varepsilon_{b}\right) \rho_{p}\left(\mathrm{~kg} S G / \mathrm{m}^{\mathrm{a}}\right) \\
q_{a}=M_{\mathrm{H}_{2} O} n_{a}\left(\mathrm{~kg} \mathrm{H} \mathrm{H}_{2} O / \mathrm{kg} S G\right)
\end{gathered}
$$

So the mass source term also can be expressed as the equation below [18]:

$$
\begin{gathered}
S_{m}=-\frac{\partial}{\partial t}\left[\left(1-\varepsilon_{b}\right) \rho_{p} M_{H_{2} O} n_{a}\right] \\
S_{m}=-\left(1-\varepsilon_{b}\right) \rho_{p} M_{H_{2} O} \frac{\partial n_{m}}{\partial t}
\end{gathered}
$$

where $\varepsilon_{b}$ is the bed porosity, $\rho_{p}\left(\mathrm{~kg} / \mathrm{m}^{3}\right)$ is the particle density of silica gel, $n_{a}(\mathrm{~mol} / \mathrm{kg})$ is the absolute adsorbed amount per unit adsorbent and $M_{H_{2} O}(\mathrm{~kg} / \mathrm{mol})$ is the molecular mass of water [20].

\subsection{Conservation of energy}

The energy balance amount compiled in the adsorption system due to the convective flow, the pressure, the conductive and thermal dispersion fluxes and the heat release, can be defined as [19]:

$$
\begin{aligned}
& \frac{\partial}{\partial t}\left[\varepsilon_{b} \rho g E_{g}+\left(1-\varepsilon_{b}\right) \rho_{p} E_{g}\right]+\nabla \cdot\left[\vec{v}\left(\rho_{g} E_{g}+p\right)\right]=\nabla \cdot \\
& \left(k_{e f f} \bar{v} T\right)+\nabla \cdot(\underline{\underline{\tau}} \cdot \vec{v})+Q
\end{aligned}
$$

where $\mathrm{E}$ is the summary of internal and kinetic energy. It can be defined as:

$$
E=h-\frac{p}{\rho}+\frac{v^{2}}{2}
$$

In the terms of left hand side of the equation, it is considering the pressure work. The impact of gravity may be neglected. The viscous dissipation $(\emptyset)$ is counted in the term $\nabla \times(\underline{\tau} \propto \vec{v})$ based on the following equation:

$$
\nabla \cdot(\underline{\underline{\tau}} \cdot \vec{v})=\vec{v} \cdot(\nabla \cdot \underline{\underline{\tau}})+\underline{\underline{\tau}}: \nabla \vec{v}=\vec{v} \cdot(\nabla \cdot \underline{\underline{\tau}})+\varphi
$$

In the energy conservation equation, the energy source term can be defined as [18]:

$$
Q=-\Delta H S_{m} / M_{\mathrm{H}_{2} \mathrm{O}}
$$

where $Q\left(\mathrm{~W} / \mathrm{m}^{3}\right)$ is the energy source term, $\Delta H(\mathrm{~J} / \mathrm{mol})$ is the isosteric heat of adsorption, and $S_{m}\left(\mathrm{~kg} / \mathrm{m}^{3} \mathrm{~s}\right)$ is the mass source term.

\subsection{Conservation of momentum}

The momentum equation can be described as the following equation [19]:

$$
\frac{\partial}{\partial t}\left(\rho_{g} \vec{v}\right)+\nabla \cdot\left(\rho_{g} \vec{v} \vec{v}\right)=-\nabla p+\nabla \cdot \underline{\underline{\tau}}+\rho_{g} \vec{g}+\vec{F}
$$

where $\vec{F}\left(\mathrm{~N} / \mathrm{m}^{3}\right)$ is the momentum source term and $\underline{\underline{\tau}}$ is the stress tensor. The momentum source term is based on the Ergun equation. It contains viscous and inertial losses. For a simple homogeneous porous media in $i$ direction, " $\mathrm{F}_{\mathrm{i}}$ ", the momentum can be expressed as [19]:

$$
F_{i}=-\frac{\mu}{K} v_{i}-C_{2} \frac{1}{2} \rho_{g}|\vec{v}|_{i}
$$

where $\mu(\mathrm{Pa} \mathrm{s})$ is the dynamic viscosity of water, $1 / \mathrm{K}$ $\left(1 / \mathrm{m}^{2}\right)$ is the viscous resistance coefficient, $C_{2}(1 / \mathrm{m})$ is the inertial resistance coefficient, $|\vec{v}|$ is the magnitude of the velocity vector and $v_{i}$ is the velocity component along the $i$ direction. 


\section{Model parameters}

\subsection{Model validation using experimental system}

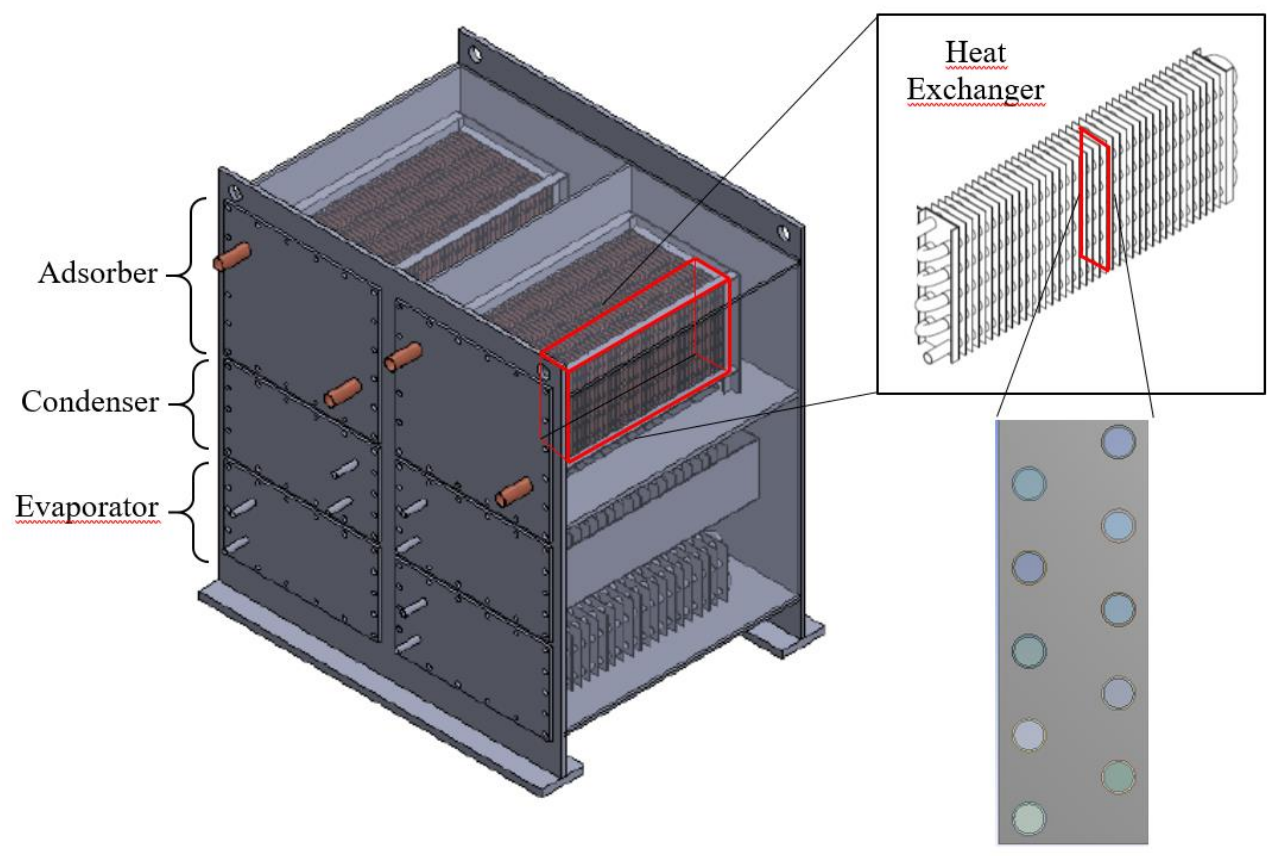

Fig. 1. The silica gel layer between two fins as the adsorbent on the adsorbent bed. [21]

The experimental study of silica gel-water adsorption chiller was developed in Mechanical Engineering of the Universitas Indonesia. The design configuration of chiller is designed of two sorption chambers that each has three sub-chambers consisting of compact fin tube heat exchangers as adsorber, condenser, and evaporator [21]. The simulations are tested under typical condition for hot water inlet/cooling water inlet/chilled water inlet temperatures are $353.15 / 305.15 / 288.15{ }^{\circ} \mathrm{K}$. The inlet cooling water pressure and the mass flow rate is set as $32000 \mathrm{~Pa}$ and $0.3 \mathrm{~kg} / \mathrm{s}$. The pressure value is $21331.6 \mathrm{~Pa}$ for the chamber of adsorber so the inlet adsorption pressure value too. The data will be recorded after getting a stable condition in several cycles in order to get easier to be analyzed.

The student version of CFD software Fluent is used to simulate the silica gel-water adsorption cooling process during adsorption and desorption. Fig. 2(a) shows
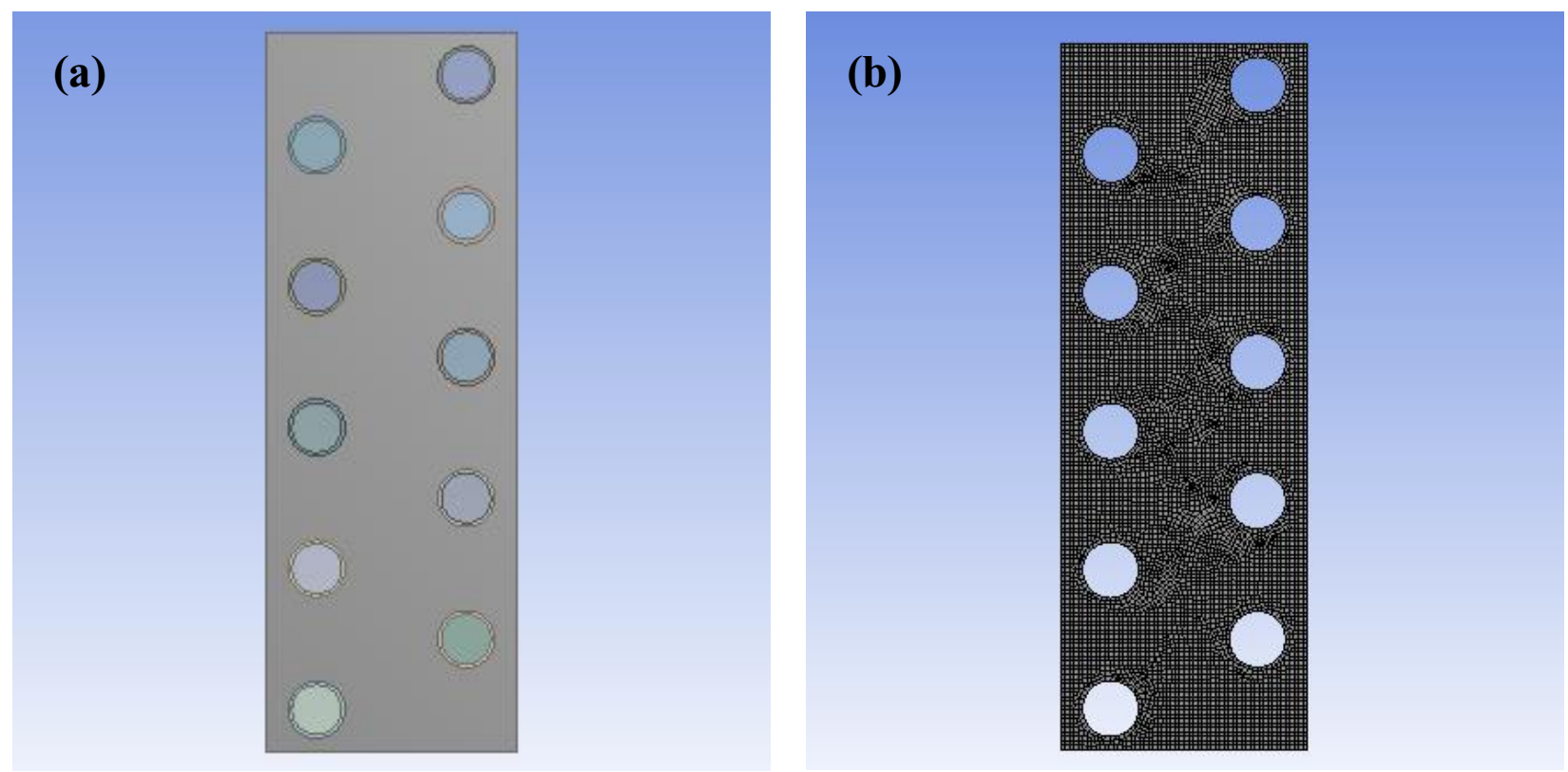

Fig. 2. Pictorial view (a) and grid view (b) of silica gel adsorbent on adsorbent bed. 
the geometric model of the adsorbent at the adsorbent bed. The wall of circle area represents the tube where the cooling water inlet flows. Fig. 2(b) shows the grid of silica gel adsorbent which has 33220 nodes. The dimensions of the geometry model and the location of the middle point of all tubes are given below.

\begin{tabular}{ll}
\hline Table 1. Geometric parameters. & \\
\hline Parameter & Value $(\mathbf{m m})$ \\
\hline Outer radius of tube & 12.7 \\
Thickness of tube & 0.8 \\
Length of adsorbent & 56 \\
Width of adsorbent & 3 \\
Height of adsorbent & 160 \\
Middle point of tube 1 & $(11.35,9.35)$ \\
Middle point of tube 2 & $(44.65,25.05)$ \\
Middle point of tube 3 & $(11.35,40.75)$ \\
Middle point of tube 4 & $(44.65,56.45)$ \\
Middle point of tube 5 & $(11.35,71.15)$ \\
Middle point of tube 6 & $(44.65,87.85)$ \\
Middle point of tube 7 & $(11.35,103.55)$ \\
Middle point of tube 8 & $(44.65,119.25)$ \\
Middle point of tube 9 & $(11.35,134.95)$ \\
Middle point of tube 10 & $(44.65,150.65)$ \\
\hline
\end{tabular}

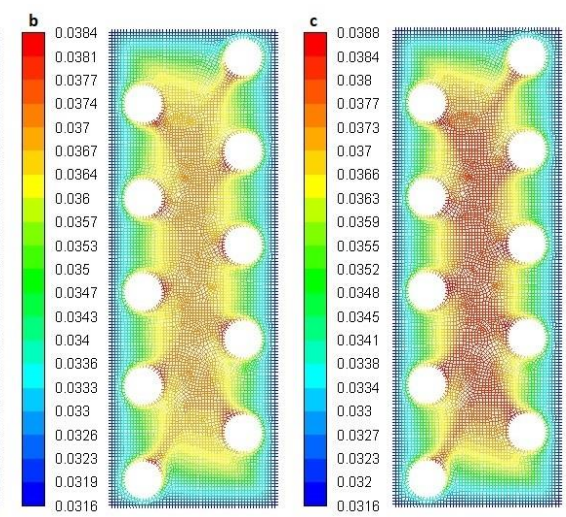

Fig. 3. Absolute adsorption contour (mol/kg) at (a) $10 \mathrm{~s}$ (b) 20 $\mathrm{s}$ and (c) $30 \mathrm{~s}$.

\subsection{Material properties}

The materials used in the simulation of the silica gelwater adsorption chiller were copper for fins and tube, water liquid for cooling water, water vapor for the refrigerant, and silica gel as solid material of porous zone.

\begin{tabular}{|c|c|c|}
\hline \multirow[t]{3}{*}{ Copper (Cu) } & Density $\left(\mathrm{kg} / \mathrm{m}^{3}\right)$ & 8978 \\
\hline & Specific heat capacity $(\mathrm{J} / \mathrm{kg} \mathrm{K})$ & 381 \\
\hline & Thermal conductivity (W/m K) & 387.6 \\
\hline \multirow{4}{*}{$\begin{array}{l}\text { Silica gel } \\
\left(\mathrm{SiO}_{2}\right)\end{array}$} & Density $\left(\mathrm{kg} / \mathrm{m}^{3}\right)$ & 2330 \\
\hline & Specific heat capacity $(\mathrm{J} / \mathrm{kg} \mathrm{K})$ & 921 \\
\hline & Thermal conductivity $(\mathrm{W} / \mathrm{m} \mathrm{K})$ & 0.174 \\
\hline & Porosity & 0.8 \\
\hline \multirow{4}{*}{$\begin{array}{l}\text { Water liquid } \\
\left(\mathrm{H}_{2} \mathrm{O}_{(\mathrm{I})}\right)\end{array}$} & Density $\left(\mathrm{kg} / \mathrm{m}^{3}\right)$ & 998.2 \\
\hline & Specific heat capacity $(\mathrm{J} / \mathrm{kg} \mathrm{K})$ & 4182 \\
\hline & Thermal conductivity (W/m K) & 0.6 \\
\hline & Viscosity $(\mathrm{kg} / \mathrm{m} \mathrm{s})$ & $1.003 \mathrm{e}-03$ \\
\hline \multirow{4}{*}{$\begin{array}{l}\text { Water vapor } \\
\left(\mathrm{H}_{2} \mathrm{O}\right)\end{array}$} & Density $\left(\mathrm{kg} / \mathrm{m}^{3}\right)$ & 0.5542 \\
\hline & Specific heat capacity $(\mathrm{J} / \mathrm{kg} \mathrm{K})$ & $\mathrm{PP}$ \\
\hline & Thermal conductivity $(\mathrm{W} / \mathrm{m} \mathrm{K})$ & 0.0261 \\
\hline & Viscosity $(\mathrm{kg} / \mathrm{m} \mathrm{s})$ & $1.34 \mathrm{e}-05$ \\
\hline
\end{tabular}

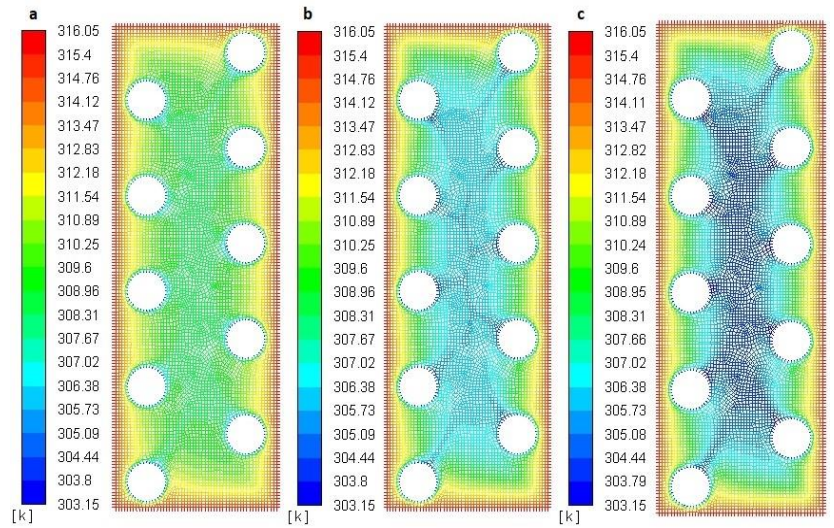

Fig. 4. Temperature contour (K) at (a) $10 \mathrm{~s} \mathrm{(b)} 20 \mathrm{~s}$ and (c) 30

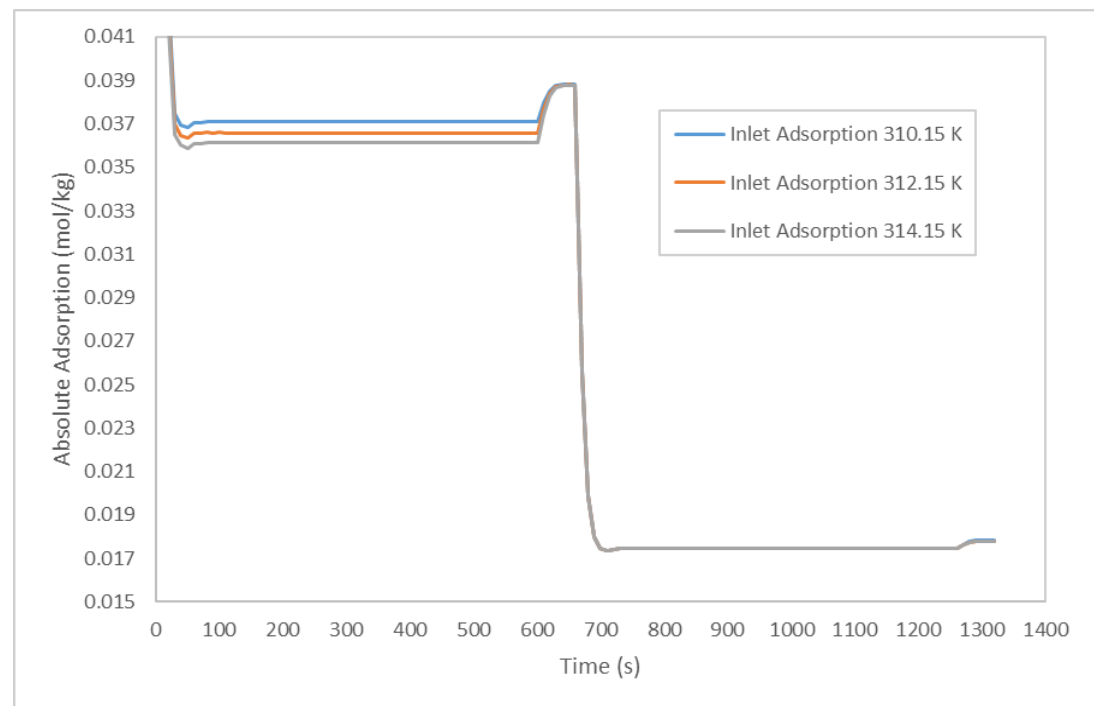

Fig. 5. Absolute adsorption as the effect of inlet adsorption temperature. 


\section{Results and discussions}

In this case, we study the changes and the contours of temperature, pressure, and adsorption during the adsorption and desorption processes.

\subsection{Grid independence analysis}

The numerical study of adsorption chiller was developed using custom quality of mesh that plays a significant role in the stability and the accuracy of CFD. Finest mesh with 33220 nodes and 23575 elements gets high increment because it is necessary to maintain minimum value of orthogonal quality at 0.5 in order to improve the convergence of calculation. The finest mesh gets good orthogonal quality with minimum value at 0.5135 .

\subsection{Absolute adsorption and temperature distributions}

By using CFD software, it can be shown using color variation per time or per position. Fig. 3 (a), (b), and (c) show the adsorption distributions at $10 \mathrm{~s}, 20 \mathrm{~s}$, and $30 \mathrm{~s}$ respectively. While Fig. 4 (a), (b), and (c) show the

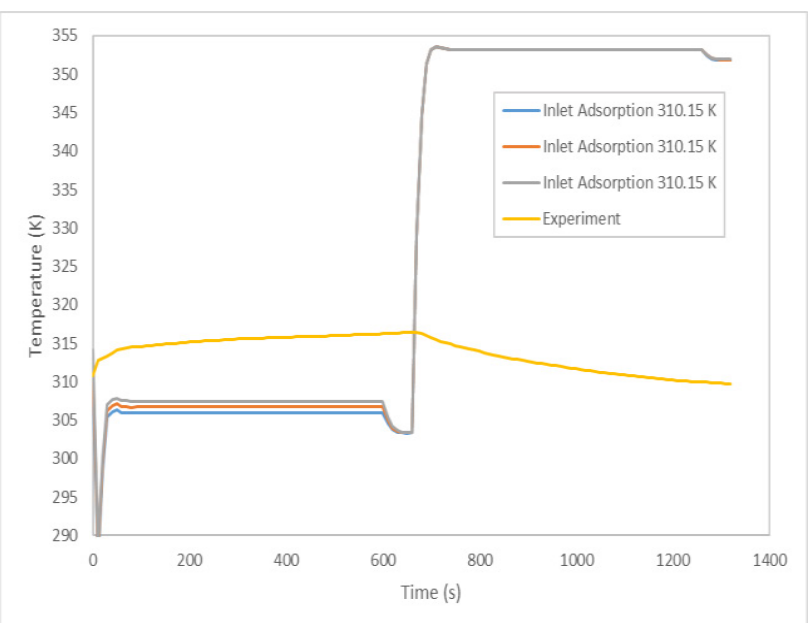

Fig. 6. Average temperature at adsorbent as the effect of inlet adsorption temperature.

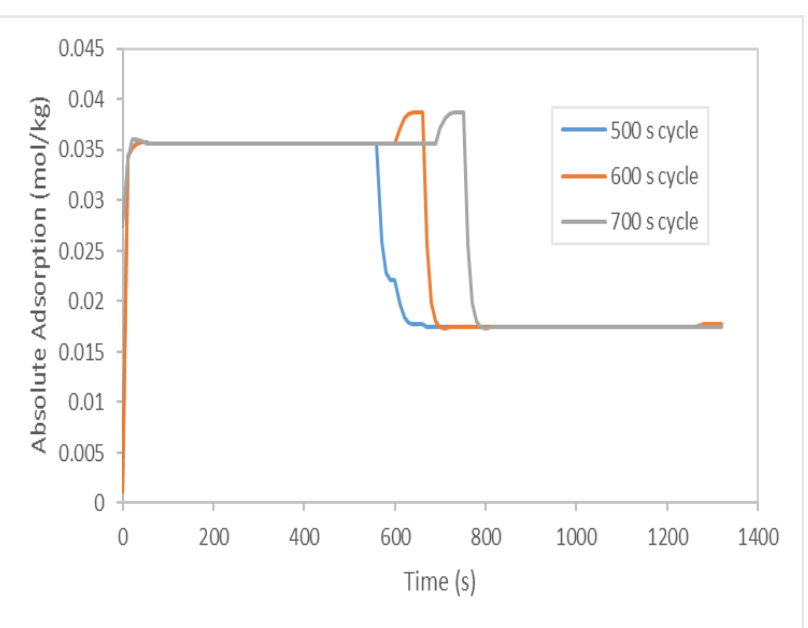

Fig. 7. Absolute adsorption as the effect of cycle time. temperature distributions at $10 \mathrm{~s}, 20 \mathrm{~s}$, and $30 \mathrm{~s}$ respectively. While the absolute adsorption contours are a reverse of the temperature contour.

\subsection{Effect of inlet adsorption temperature}

Fig. 5 shows the effect of different inlet adsorption temperature on the absolute adsorption. At the adsorption process, it shows the different value of absolute adsorption, while at the desorption process, there are no significant difference. Fig. 6 shows the effect of different inlet adsorption temperature on the average temperature. At the adsorption process, it shows the difference while at the desorption shows the same.

\subsection{Effect of adsorption and desorption process cycle time}

We compare the cycle time in three cases $(500 \mathrm{~s}, 600 \mathrm{~s}$, and 700 s). Fig. 7, Fig. 8, and Fig. 9 shows the effect of cycle time on the absolute adsorption. At the absolute adsorption and the average temperature, $500 \mathrm{~s}$ cycle time shows a different pattern when compared to $600 \mathrm{~s}$ and 700

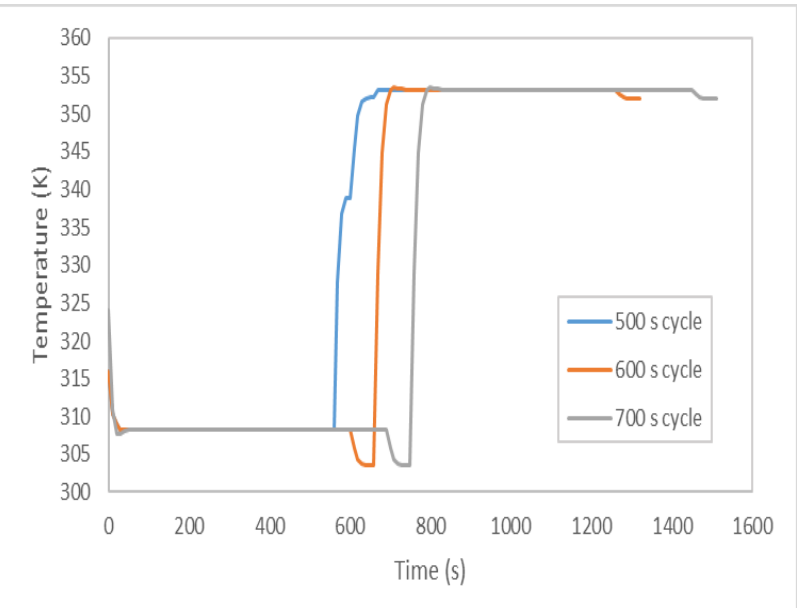

Fig. 8. Average temperature at adsorbent as the effect of cycle time.

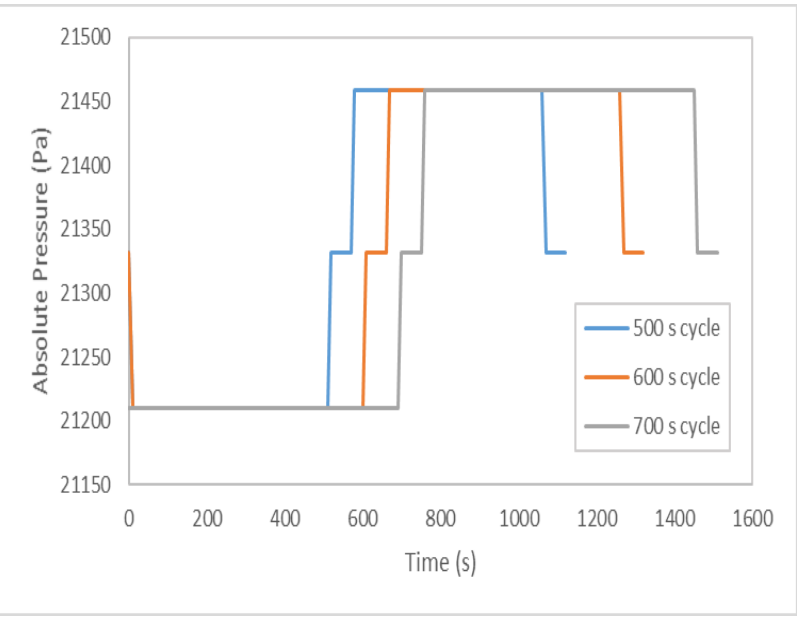

Fig. 9. Average pressure at adsorbent as the effect of cycle time. 


\section{Conclusions}

In this study, a CFD model is built while the silica gelwater adsorption and desorption processes are simulated with room temperature for cooling water inlet at temperature $305.15{ }^{\circ} \mathrm{K}$, hot water inlet at temperature $353.15^{\circ} \mathrm{K}$, mass flow rate cooling water inlet at $0.3 \mathrm{~kg} / \mathrm{s}$ and pressure $32 \mathrm{KPa}$. We study the changes of absolute adsorption, temperature, and pressure during the adsorption and desorption processes as well as the machine in idle mode. We also study about the effects of inlet adsorption temperature and cycle time in order to get a picture how the function of time can affect the average of absolute adsorption, temperature, and pressure. During the adsorption process, the silica gel layer absolute adsorption distribution shows the absolute adsorption at central area is higher than near the wall, while the silica gel layer temperature distribution shows the temperature at central area is lower than near the wall.

\section{Acknowledgement}

This experimental and numerical studies are supported by Hibah PITTA 2018 funded by DRPM Universitas Indonesia No.5000/UN2.R3.1/HKP.05.00/2018.

\section{References}

1. A. Pal, K. Thu, S. Mitra, I.I. El-Sharkawy, B.B. Saha, H.-S. Kil, S.-H. Yoon, J. Miyawaki, Study on biomass derived activated carbons for adsorptive heat pump application, Int. J. Heat Mass Transf. 110 (2017) 7-19

2. I.I. El-Sharkawy, K. Uddin, T. Miyazaki, B. Baran Saha, S. Koyama, H.S. Kil, S.H. Yoon, J. Miyawaki, Adsorption of ethanol onto phenol resin based adsorbents for developing next generation cooling systems, Int. J. Heat Mass Transf. 81 (2015) 171178

3. B. Shi, R. AL-Dadah, S. Mahmoud, A. Elsayed, E. Elsayed, CPO-27(Ni) metal-organic framework based adsorption system for automotive air conditioning, Appl. Therm. Eng. 106 (2016) 325333

4. K. Uddin, I.I. El-Sharkawy, T. Miyazaki, B.B. Saha, S. Koyama, Thermodynamic analysis of adsorption cooling cycle using ethanol - surface treated Maxsorb III pairs, Evergr. Jt. J. Nov. Carbon Resour. Sci. Green Asia Strateg. 1 (2014) 25-31

5. A. Pal, M.S.R. Shahrom, M. Moniruzzaman, C.D. Wilfred, S. Mitra, K. Thu, B.B. Saha, Ionic liquid as a new binder for activated carbon based consolidated composite adsorbents, Chem. Eng. J. 326 (2017) 980-986

6. J. Yan, Y. Yu, J. Xiao, Y. Li, Z. Li, Improved ethanol adsorption capacity and coefficient of performance for adsorption chillers of $\mathrm{Cu}$ BTC@GO composite prepared by rapid room temperature synthesis, Ind. Eng. Chem. Res. 55 (2016) 11767-11774
7. I.I. El-Sharkawy, A. Pal, T. Miyazaki, B.B. Saha, S. Koyama, A study on consolidated composite adsorbents for cooling application, Appl. Therm. Eng. 98 (2016) 1214-1220

8. L. Jiang, Y.J. Lu, K. Tang, Y.D. Wang, R. Wang, A.P. Roskilly, L. Wang, Investigation on heat and mass transfer performance of novel composite strontium chloride for sorption reactors, Appl. Therm. Eng. 121 (2017) 410-418

9. S. Mitra, N. Aswin, P. Dutta, Scaling analysis and numerical studies on water vapour adsorption in a columnar porous silica gel bed, Int. J. Heat Mass Transf. 95 (2016) 853-864

10. M. Mahdavikhah, H. Niazmand, Effects of plate finned heat exchanger parameters on the adsorption chiller performance, Appl. Therm. Eng. 50 (2013) 939-949

11. A. Li, K. Thu, A. Bin Ismail, M.W. Shahzad, K.C. $\mathrm{Ng}$, Performance of adsorbent embedded heat exchangers using binder-coating method, Int. J. Heat Mass Transf. 92 (2016) 149-157

12. I.S. Girnik, Y.I. Aristov, Dynamic optimization of adsorptive chillers: the "AQSOATM-FAM-Z02 water" working pair, Energy 106 (2016) 13-22

13. A.K. Jaiswal, S. Mitra, P. Dutta, K. Srinivasan, S. Srinivasa, Murthy, influence of cycle time and collector area on solar driven adsorption chillers, Sol. Energy 136 (2016) 450-459

14. K. Thu, B.B. Saha, S. Mitra, K.J. Chua, Modeling and simulation of mass recovery process in adsorption system for cooling and desalination, Energy Procedia 105 (2017) 2004-2009

15. Saha, B.B., Koyama, S., Choon Ng, K., Hamamoto, Y., Akisawa, A., Kashiwagi, T., Study on a dualmode, multi-stage, multi-bed regenerative adsorption chiller. Renew. Energy 31 (2006) 20762090

16. Delahaye A, Aoufi A, Gicquel A. Improvement of hydrogen storage by adsorption using 2-D modeling of heat effects. AIChE $\mathbf{J}$ (2002) 48:2061-73

17. Lamari M, Aoufi A, Malbrunot P. Thermal effects in dynamic storage of hydrogen by adsorption. AIChE J (2000) 46:632-46

18. Xiao JS, Tong L, Deng CH. Simulation of heat and mass transfer in activated carbon tank for hydrogen storage. Int J Hydrogen Energy 35 (2010) 8106-16

19. ANSYS, Inc. FLUENT 12.0 user's guide (2013)

20. J. Xiao, R. Peng, D. Cossement, P. Benard, R. Chahine, CFD Model for adsorptive hydrogen storage. Int J Hydrogen Energy 38 (2013) 1450-59

21. A. Taufan. Design and experimental study on silica gel-water adsorption chiller. (2017) 